\title{
A novel thermo- ethanol tolerant Acetobacter okinawensis KBMNS-IAUF-1 isolated from Iranian nectarine as a potential for nectarine vinegar production in food biotechnology
}

Keivan Beheshti-Maal ( $\sim$ beheshtimaal@iaufala.ac.ir)

Falavajan Branch, Islamic Azad University https://orcid.org/0000-0003-3226-4783

Noushin Shafiee

Falavarjan Branch, Islamic Azad University

Research article

Keywords: Acetic acid, Acetobacter okinawensis, Fermentation, Food biotechnology, Iranian nectarine, Vinegar.

Posted Date: July 26th, 2019

DOl: https://doi.org/10.21203/rs.2.11979/v1

License: (c) (i) This work is licensed under a Creative Commons Attribution 4.0 International License. Read Full License 


\section{Abstract}

Background Recently production of several types of vinegar using new strains of acetic acid bacteria is challenging. Results In this research we isolated a new strain of A. okinawensis from Iranian nectarine we obtained from nectarine garden at Isfahan, Iran. According to 16s-rDNA molecular analysis we named that Acetobacter okinawensis strain KBMNS-IAUF-1 and its partial 16s-rDNA sequence was deposited in GenBank, NCBI under the accession number of MG544095.1. The tolerance of A. okinawensis KBMNSIAUF-1 against ethanol concentrations of $2 \%-10 \%$ and high temperatures of $34-38^{\circ} \mathrm{C}$ was investigated. This strain had good growth and acid production in $2 \%-5 \%$ ethanol at high temperature of $38^{\circ} \mathrm{C}$ and as a thermo-tolerant $A A B$ had good growth in $5 \%$ ethanol at $38^{\circ} \mathrm{C}$. Also produced $6 \%$ acetic acid in an economical industrial culture medium at high temperature of $38^{\circ} \mathrm{C}$ using a fermentor apparatus we designed for vinegar production. Conclusions This is the first report of isolation and identification of Acetobacter okinawensis KBMNS-IAUF-1 from Iranian nectarine as a high thermo- ethanol- tolerant AAB capable of high acetic acid production in a short period of time and is a very good candidate for production of a new type of vinegar, nectarine vinegar, in high temperatures and ethanol concentrations. The thermo- ethanol-tolerant $A A B$ as potential for production of new types of vinegar with suitable flavor could be an asset in food microbiology as well as industrial biotechnology.

\section{Background}

The US Food and Drug Administration (FDA) has defined the sour wine or vinegar as a $4 \%$ liquid of acetic acid ( $4 \mathrm{~g}$ of acetic acid in each $\mathrm{cm}^{3}$ ) that has been generated through alcoholic fermentation of sugary and sweet precursors [1, 2]. Natural vinegar as a popular food flavoring and supplement has several essential amino acids according to its fruit source and could be applied for relieving the pains especially those occurred in the human gastrointestinal tract $[3,4]$. The acetic acid bacteria (AAB) are Gram negative aerobic rods that are responsible for vinegar production through biological oxidation $[5,6]$. While more than 30 years ago the AAB were divided to two genera of Acetobacter and Gluconobacter but recently this classification has been considerably changed. According to modern molecular classification of $16 \mathrm{~s}$ ribosomal DNA analysis, the AAB are related to family of Acetobacteriaceae and classified in 19 genera of Acetobacter, Acidomonas, Ameyamaea, Asaia, Bombella, Commensalibacter, Endobacter, Gluconacetobacter, Gluconobacter, Granulibacter, Komagataeibacter, Kozakia, Neoasaia, Neokomagataea, Nguyenibacter, Saccharibacter, Swaminathania, Swingsia and Tantichar- oenia [3, 7, 8, 9]. The use of identified pure $A A B$ could increase the production of vinegar and the industrial vinegar producers are looking for new $A A B$ capable for manufacturing attractive types of natural vinegars socially $[2,5,10]$. Various primary substrates have been used for vinegar production such as bee honey [11], rice [12], sugarcane [4] and balsam [13-15]. Among AAB, Acetobacter spp. As the main responsible microorganism for vinegar production have been isolated from several natural resources such as grape, date and coconut [16-18], Iranian white-red cherry [19, 20], Iranian peach [1, 21], Iranian apricot [22], Jamaican cherry, pineapple, rambutan, mango and longan [23, 24], palm wine and palm tree [25-27] and Iranian date palm, Rotab [5]. The aims of this research were isolation and identification of AAB from 
Iranian nectarine as well as investigation of their tolerance against high temperatures and ethanol concentrations. Also the production of acetic acid by newly isolated $A A B$ in a miniature fermentor was discussed.

\section{Results}

Primary isolation of AAB from Iranian nectarine extract. The culture of Iranian nectarine extract to Frateur medium after 48 hours' incubation at $30^{\circ} \mathrm{C}$ resulted in the appearance of colonies that could make acid and transparency around individual colonies. The growth of isolate in this medium and acid production after incubation time confirmed that the isolated bacterium was related to AAB (Figure 1A).

Screening of Acetobacterspp. from Iranian nectarine extract. The passage of AAB individual colonies from Frateur medium to Carr medium and incubation at $30^{\circ} \mathrm{C}$ for 24 hours showed the colonies that could convert the blue color of bromocresol green of Carr medium to yellow with acetic acid fermentation (Figure 1B). The reemerging of blue color in Carr medium after 96 hours' incubation (Figure 1C) confirmed the over-oxidation ability of isolate and proposed that the isolated sp. from Iranian nectarine was related to the genus Acetobacter and the family of Acetobacteriaceae.

Macroscopic, microscopic and biochemical characterization of Acetobacter isolate. The macroscopic characteristics of isolated $A A B$ from Iranian nectarine in Frateur and Carr media including the colony morphology, color and smell were evaluated. The Gram staining of the AAB isolate showed the Gram negative bacilli and coccobacilli (Figure 2). The primary results of oxidase and catalase tests indicated that the isolated $A A B$ from Iranian nectarine was related to Acetobacter spp. The results of biochemical examinations confirmed that the isolated Acetobactersp. was Acetobacter okinawensis. The macroscopic, microscopic and biochemical examinations of the isolated AAB were indicated in Table 1.

Molecular identification of Acetobacter strain isolated from Iranian nectarine. The amplification of $16 \mathrm{~s}$ rDNA gene from extracted Iranian nectarine Acetobacter DNA using universal primers of OF BUI and OR $\mathrm{BUI}$ showed a $370 \mathrm{bp}$ product after electrophoresis and transillumination. The amplification of 16s-rDNA genes of extracted DNA from two standard strains of Escherichia coli ATCC25922 and Acetobacter aceti ATCC23746 as positive controls showed the same band of $370 \mathrm{bp}$ (Figure 3). The BLASTN analysis of 16s-rDNA sequence from Acetobacter strain showed $92 \%$ similarity and $96 \%$ query coverage with Acetobacter okinawensis strain SZCPY2 (GenBank accession number: KU555380.1). These molecular analyses indicated that the isolated $A A B$ strain from Iranian nectarine sample was related to the species of Acetobacter okinawensis. This strain was named Acetobacter okinawensis strain KBMNS-IAUF-1 and its 16s-rDNA gene partial sequence was deposited in GenBank, NCBI under the accession number of MG544095.1. Figure 4 shows the phylogenic tree of different spp. of Acetobacter and the position of currently identified Acetobacter okinawensis KBMNS-IAUF-1.

\section{The tolerance of Acetobacter okinawensis KBMNS-IAUF-1 against ethanol concentrations and high}

temperatures. The results of growth rates and acid production of Acetobacter okinawensis KBMNS-IAUF1 in modified Carr media with different ethanol concentrations of $2 \%-10 \%$ after $24-96$ hours' incubation at 
$34^{\circ} \mathrm{C}$ has been indicated in Table 2. The effects of ethanol concentrations of $2 \%-10 \%$ and the high temperature of $36^{\circ} \mathrm{C}$ against the growth rates and acid production by Acetobacter okinawensis KBMNSIAUF-1 was shown in Table 3. The results of growth rates and acid production of Acetobacter okinawensis KBMNS-IAUF-1 in modified Carr media with different ethanol concentrations of $2 \%-10 \%$ after $24-96$ hours' incubation at $38^{\circ} \mathrm{C}$ has been indicated in Table 4 .

\section{Acetic acid production using isolated Acetobacter okinawensis KBMNS-IAUF-1 from Iranian nectarine in} industrial culture medium. The cultivation of Acetobacter okinawensis KBMNS-IAUF-1 in miniature glass fermentor containing $500 \mathrm{ml}$ industrial medium was led to production of a new type vinegar with a good smell, flavor and appearance after 24 hours of fermentor operation. The acetic acid titration assay of fermented industrial culture medium containing this newly discovered AAB strain after $24,48,72,96,120$, 144 and 168 hours of incubation at $38^{\circ} \mathrm{C}$ and $16 \mathrm{LPM}$ of aeration speed indicated the elevation of acetic acid percentage of $3.6 \%, 3.72 \%, 4.77 \%, 5.36 \%, 5.58 \%, 6 \%$ and $6 \%$ respectively. The results confirmed that Acetobacter okinawensis KBMNS-IAUF-1 isolated from Iranian nectarine could produce a considerable amount of acetic acid in a short period of time. Figure 5 shows the production of acetic acid by Acetobacter okinawensis KBMNS-IAUF-1 in industrial culture medium using a miniature glass fermentation vessel.

\section{Discussion}

Manufacturing high acetic acid concentration in acetators is challenging and finding new ethanol-tolerant AAB strains could be an asset in vinegar industry as well as food biotechnology $[3,28]$. The most Acetobacterspp. that have been reported for vinegar production are A. aceti, A. cerevisiae, A. malorum, $A$. oeni, A. pasteurianus and A. pomorum [7, 29]. At the first time Acetobacter okinawensis was isolated from sugarcane stem in 2004 at Okinawa, Japan. Then isolated from grape, Japanese plum and oriental melon in 2007 at Okayama, Japan [30]. Chen et al. (2016) have reported the isolation of a AAB as $A$. okinawensis from Tibetan kefir [31]. In another study was reported that $A$. okinawensis has been frequently isolated in samples related to apple resources. Also suggested that the specific gene-based sequence analysis is effective for $A A B$ discrimination [29]. In this research we isolated a new strain of $A$. okinawensis from Iranian nectarine we obtained from nectarine garden at Isfahan, Iran. According to $16 \mathrm{~s}-$ rDNA molecular analysis we named that Acetobacter okinawensis strain KBMNS-IAUF-1 and its partial 16s-rDNA sequence was deposited in GenBank, NCBI under the accession number of MG544095.1. Sharafi et al. (2010) used GYC culture medium for isolation and screening of AAB from several fruits samples [21]. Klawpiyapamornkun et al. (2015) used a synthetic medium of normal saline and ethanol for enrichment and isolation of $A A B$ from fruits and fermented fruit juices [9]. In this research we used Frateur culture medium for screening $A A B$ and then Carr medium for $A A B$ overoxidation activity and isolating the Acetobacterspp. as the most privileged $A A B$ spp. for industrial production of vinegar. Both mentioned media were economic and easy to handle biotechnologically. In a research study, AAB growth in the presence of $4 \%-10 \%$ ethanol concentrations were examined. There were indicated that all of $A A B$ isolates were able to grow optimally in the concentrations of $4 \%-6 \%$ ethanol [9]. In a research an Acetobactersp. that was isolated from Iranian peach could successfully tolerate against $2.5 \%-5 \%$ ethanol 
in high temperatures of $34-40^{\circ} \mathrm{C}$ after 96 hours' incubation [1]. In another study was indicated that the elevation of ethanol concentration from $2 \%$ to $9 \%$ in culture medium is led to the high sensitivity of an Acetobactersp. isolated from Rotab to high temperatures of $34-38^{\circ} \mathrm{C}$ [5]. So far there is no report of optimization of $A$. okinawensis acid production and growth rates using cultivation in high ethanol concentration and temperatures simultaneously. In the present study, the tolerance of $A$. okinawensis KBMNS-IAUF-1 against ethanol concentrations of $2 \%-10 \%$ and high temperatures of $34-38^{\circ} \mathrm{C}$ was investigated. The results suggested that at $34^{\circ} \mathrm{C}$, the $2 \%-5 \%$ ethanol had no effects on the growth of $A$. okinawensis KBMNS-IAUF-1. The $6 \%$ ethanol between 24-72 hours' incubation decreased the growth rate and acetic acid production a little but after 96 hours we had the maximum growth. The ethanol concentrations of $7 \%-8 \%$ reduced the growth and acid production considerably. There was no growth at ethanol concentrations of $9 \%-10 \%$ at $34^{\circ} \mathrm{C}$. At higher temperatures of $36^{\circ} \mathrm{C}$ the sensitivity of isolated $A A B$ strain to higher ethanol percentages was more obvious so that the isolated strain had good growth and acetic acid production in $2 \%-5 \%$ ethanol but in $6 \%$ ethanol the growth rate was declined and had no growth in $7 \%-10 \%$ ethanol at $36^{\circ} \mathrm{C}$. The $A$. okinawensis KBMNS-IAUF-1 had good growth and acid production in $2 \%-5 \%$ ethanol at high temperature of $38^{\circ} \mathrm{C}$ but in $6 \%$ ethanol lost the growth obviously. There was no growth and acetic acid production in $\geq 6 \%$ ethanol. These results suggested that the extreme conditions of high ethanol concentrations and temperatures could prevent the growth rate and subsequently the acetic acid production by $A$. okinawensis KBMNS-IAUF-1 isolated from Iranian nectarine. However, this strain as a thermo-tolerant $A A B$ had good acetic acid production in $5 \%$ ethanol at $38^{\circ} \mathrm{C}$. Klawpiyapamornkun et al. (2015) showed that using rotary shaker incubator and a medium containing $2 \%$ ethanol and $2 \%$ yeast extract, their $\mathrm{AAB}$ isolates of P1, P4, P6, P12 and Acetobacter aceti produced acetic acids percentage of $1.78,1.80,1.80,1.81$ and 1.81 respectively [9]. Diba et al. (2015) reported that their isolated AAB from decomposed fruits in YGEA medium containing yeast extract, glucose, ethanol and acetic acid at $37^{\circ} \mathrm{C}$ after 72 hours' incubation made $3-6 \%$ acetic acid. While the glucose has induced the acetic fermentation in a considerable manner in their research but is not economic in industrial purposes [32]. While in previous studies we reported the optimal growth of $A A B$ in 2-5\% ethanol, the AAB were identified as Acetobacter spp. and they were not identified at the levels of species and strain using biochemical test and then molecular identifications $[1,5,19,20,22]$ so the identification of a novel $A A B$ at the molecular level is the first important aspect of this study in comparison to previous researches. The second importance of this work is the isolation of Acetobacter okinawensis from nectarine fruit that is reported for the first time in the world. The third importance of this study was finding a AAB could grow in 6-8\% ethanol concentrations and simultaneously in high temperatures of $36-38^{\circ} \mathrm{C}$. As it was indicated in Table 2, the $A$. okinawensis KBMNS-IAUF-1 had very good growth in $6-8 \%$ of ethanol concentrations at $34^{\circ} \mathrm{C}$ in modified Carr media. Also Table 2 and 3 indicated that the isolated strain had good growth in $6-7 \%$ of ethanol concentrations at $36^{\circ} \mathrm{C}$ and $38^{\circ} \mathrm{C}$ respectively. The Acetobacter spp. usually grow in mesophilic temperatures of $28-30^{\circ} \mathrm{C}$ while the keeping of industrial acetators in these temperatures is costly so finding the thermo-tolerant Acetobacter spp. is considered as an asset biotechnologically. The growth of $A$. okinawensis KBMNS-IAUF-1 in high temperatures if could be translated to industrial concepts and in a 100,000 liter acetator means a very high amount of energy saving during a vinegar production batch that takes long 1-2 weeks in an advanced high-tech facility. The 
tables 2 to 4 have shown the growth of $A$. okinawensis KBMNS-IAUF-1 in solid culture media but the most important aspect of this study was the thermal and acetic acid tolerance of this new strain in a simulated industrial broth medium. As it was inferred from Figure 5 , this strain was able to grow at high temperature of $38^{\circ} \mathrm{C}$ in $6 \%$ acetic acid concentration. The acetic acid was obtained from ethanol during the acetic fermentation of $A A B$, so the ability of this strain to grow in broth industrial medium in the extreme condition of high temperature of $38^{\circ} \mathrm{C}$ in the presence of $2 \%$ ethanol and $6 \%$ acetic acid in 7 days' incubation is similar to grow in a broth medium containing $8 \%$ ethanol and is considered as a very significant trait of $A$. okinawensis KBMNS-IAUF-1 that is reported for the first time in the world.

\section{Conclusions}

This is the first report of isolation and identification of Acetobacter okinawensis KBMNS-IAUF-1 from Iranian nectarine. Also the optimization of growth rate as well as acetic acid production in the extreme conditions of high temperatures and ethanol concentrations have been investigated for the first time. The A. okinawensis KBMNS-IAUF-1 had maximum growth rate and acid production in $6 \%$ ethanol at $34^{\circ} \mathrm{C}$ after 96 hours' incubation. The maximum acid production and growth of this newly discovered $A A B$ strain at $36^{\circ} \mathrm{C}$ and $38^{\circ} \mathrm{C}$ were obtained in ethanol concentrations of $4 \%$ and $3 \%$ respectively after 96 hours' incubation. The results of this research confirmed that A. okinawensis KBMNS-IAUF-1 isolated from Iranian nectarine not only could tolerate against high ethanol concentrations and high temperatures but also resist in high concentrations of acetic acid and could be considered as a potential AAB strain for production of vinegar with high rancidity of $6 \%$ in a very short period of time, 5 days, industrially. So the A. okinawensis KBMNS-IAUF-1 as a thermo- ethanol-tolerant AAB strain is a very good candidate for production of a new type of vinegar, nectarine vinegar, in high temperatures and ethanol concentrations. The thermo- ethanol-tolerant $A A B$ could be considered as potential for vinegar production in food microbiology as well as industrial biotechnology.

\section{Methods}

Chemicals and microbiological culture media. The main chemicals we used were ethanol $96 \%$ (Razi, Iran), yeast extract (Taligene, Iran), acetic acid, agar agar, D-glucose, $\mathrm{CaCO}_{3}$, bromocresol green, $\mathrm{NaOH}$ and phenolphthalein (all from Merck, Germany). The microbiological culture media were Brain Heart Infusion Broth (BHI) from Himedia, India, Frateur medium $\left(\mathrm{CaCO}_{3}, 20 \mathrm{~g} / \mathrm{l}\right.$; yeast extract, $10 \mathrm{~g} / \mathrm{l}$; ethanol, $20 \mathrm{~g} / \mathrm{l}$; agar agar, $20 \mathrm{~g} / \mathrm{l}$; distilled water, $1000 \mathrm{ml}$ ), Carr medium (yeast extract, 3\%; bromocresol green, $0.002 \%$, ethanol $2 \%$, agar agar, 2\%; DW, $1000 \mathrm{ml}$ ) and modified Carr media with different ethanol concentrations of $3 \%, 4 \%$, $5 \%, 6 \%, 7 \%, 8 \%, 9 \%$ and $10 \%$. Also an industrial culture medium (yeast extract, $1 \%$; acetic acid, $2 \%$; ethanol, $2 \%$ and $\mathrm{DW}, 1000 \mathrm{ml}$ ) was used.

Iranian nectarine sampling and preparation. The both intact and spoiled Iranian nectarine samples were provided from nectarine garden, Isfahan, Iran. Using sterile container, the fruits were transferred at $4^{\circ} \mathrm{C}$ to the laboratory of microbiology, R\&D laboratories complex, Falavarjan Branch, Islamic Azad University, Isfahan, Iran. The fruits were placed in sterile plastic bag with openings at room temperature and 
appropriate ventilating condition for 7-10 days. After emerging fruit flies and vinegar smelling from container, the fruits were pressed, scrutinized and homogenized and then transferred to a sterile plastic bottle and its cap was closed. For preventing the bottle burst during alcoholic fermentation and $\mathrm{CO}_{2}$ accumulation, some tiny openings were made with needle on the top of bottle. The bottle was incubated at $30^{\circ} \mathrm{C}$ for 7 days [5].

Primary isolation of AAB from Iranian nectarine extract. Ten milliliters of nectarine extract were added to $90 \mathrm{ml}$ sterile distilled water to make $10^{-1}$ dilution. One standard loop of mentioned dilution was cultured on Frateur medium using streak plate method. The medium was incubated at $30^{\circ} \mathrm{C}$ for $24-48$ hours. The individual colonies with transparent surrounding were collected and purified in the same condition $[1,5]$.

Screening of Acetobacterspp. from Iranian nectarine extract. The purified AAB from previous stage were cultured on Carr media using streak plate method and incubated at $30^{\circ} \mathrm{C}$ for $24-48$ hours. Those yellow colonies after 24 hours' incubation that were converted to blue ones after 48 hours' incubation were selected and purified using the same condition and preserved at $-70^{\circ} \mathrm{C}$ in Carr medium included $50 \%$ glycerol for next experiments [21].

Macroscopic, microscopic and biochemical characterization of Acetobacter isolate. The colony characterization of isolated Acetobacter strain from Iranian nectarine was performed using stereomicroscopy. The microscopic traits were detected after Gram staining of purified colonies in Frateur and Carr media. The individual purified colonies were examined against catalase and oxidase reaction, acid production and making transparent in Frateur medium and overoxidation ability in Carr medium [22]. For identification of the genus and species of the isolated $A A B$, the complement biochemical examinations were fulfilled. These tests were production of ketogluconic acids, production acid from $D$ glucose, D-galactose, D-mannose, D-xylose, L-arabinose and growth on 30\% D-glucose. All tests were done in triplicate [33]. For confirmation of biochemical examinations all the aforementioned tests were simultaneously performed using a standard strain of Acetobacter okinawensis NRIC 0659 as positive control, that was provided from Taligene Pars Co., ISTT, Isfahan, Iran.

\section{Molecular identification of Acetobacter strain isolated from Iranian nectarine using 16s-rDNA analysis. An} individual colony of the Acetobacter isolate in Carr medium was transferred to $50 \mathrm{ml}$ of sterile distilled water. Ten milliliters of suspension were transferred to $15 \mathrm{ml}$ sterile falcon and centrifuged at $3000 \mathrm{~g}$ for 15 minutes. The supernatant was discarded and $1 \mathrm{mg}$ of bacterial biomass was used for DNA extraction by DNA extraction kit (Bioneer, South Korea). The universal primers used, were OF BUl as the forward primer with the sequence of 5'AACTGGAGGAAGGTGGGGAT3' and OR BUI as the reverse primer with the sequence of 5'AGGAGGTGATCCAACCGCA3'. PCR was performed in an Eppendorf Thermal Cycler. The PCR program encompassed initial denaturation at $96^{\circ} \mathrm{C}$ for 4 minutes, followed by 30 cycles of $94^{\circ} \mathrm{C}$ for 2 minutes, $55^{\circ} \mathrm{C}$ for 1 minute and $72^{\circ} \mathrm{C}$ for 1 minute respectively. The final steps were $72^{\circ} \mathrm{C}$ for 4 minutes and incubation at $4^{\circ} \mathrm{C}$ for 10 minutes. The expected molecular weight of PCR product was $370 \mathrm{bp}$ [21, 27]. The PCR product and primers were sent to Taligene Pars Co., Isfahan Science and Technology Town (ISTT), Isfahan, Iran for DNA sequencing. The DNA sequence was reviewed using Finch TV V.1.4.0 and 
Mega 6 software and its similarity to GenBank genomic sequences was investigated using BLASTN software (http://blast.ncbi.nlm.nih.gov). The isolated strain was identified after bioinformatics analysis and its 16s-rDNA sequence was deposited in GenBank, NCBI.

\section{The tolerance of Iranian nectarine Acetobacter strain against ethanol concentrations and high}

temperatures. The isolated Acetobacter strain from Iranian nectarine was cultured on modified Carr media with $3,4,5,6,7,8,9$ and $10 \%$ ethanol concentrations using streak plate method and incubated at high temperatures of 34,36 and $38^{\circ} \mathrm{C}$ for $24-96$ hours. Every $24 \mathrm{~h}$, the growth rate and acid production of isolated Acetobacter strain on culture media was measured. All experiments were fulfilled in triplicate and the mean of growth rate in each test was considered as the growth rate. The growth of bacterium in Carr medium with $2 \%$ ethanol was considered as control $[1,5]$.

Acetic acid titration assay. The titration assay of the produced acetic acid by isolated strain from Iranian nectarine was done as follow. Five milliliters of the broth medium were added to $20 \mathrm{ml}$ of distilled water in an Erlenmeyer flask and then a couple of phenolphthalein drops [phenolphthalein, $0.1 \mathrm{~g}$; ethanol, $60 \mathrm{~g}$; distilled water, $40 \mathrm{~g}$ ] were added. The 0.5 normal sodium hydroxide [ $\mathrm{NaOH}, 20 \mathrm{~g} / \mathrm{l}$; distilled water, $1000 \mathrm{ml}]$ were added using $50 \mathrm{ml}$ burette to acetic acid solution until appearance of pale pink color in the flask. The volume of consumed $\mathrm{NaOH}$ was measured and the acetic acid percentage in each medium was calculated $[21,22]$.

\section{Acetic acid production using isolated Acetobacter strain from Iranian nectarine in industrial culture} medium. For assessment of isolated AAB from Iranian nectarine as a potential agent for production of nectarine vinegar, the strain was cultured in $50 \mathrm{ml}$ of industrial broth medium for vinegar production [ethanol, 2\%; acetic acid, 2\%, yeast extract, 1\%, DW, $1000 \mathrm{ml}$ ] and incubated at $38^{\circ} \mathrm{C}$ and $120 \mathrm{rpm}$ for 24 hours. After emerging the vinegar smell from the medium, the whole $50 \mathrm{ml}$ transferred to $1000 \mathrm{ml}$ miniature glass fermentor (Taligene Pars Co., ISTT, Iran) containing $500 \mathrm{ml}$ of industrial culture medium. The sterile air sparging pump speed was set on 16 LPM and fermentor was incubated at $38^{\circ} \mathrm{C}$ for 168 hours. Every 24 hours the acetic acid elevation was measured using previously described acetic acid titration assay. After titration completed, $2 \%$ extra-ethanol were added to fermentor using aseptic method and the fermentor set up to the same condition i.e was let to continue to ferment ethanol to acetic acid until the maximum acetic acid titer was reached $[19,20]$.

\section{Declarations}

\section{Ethics approval and consent to participate}

Not applicable

\section{Consent for publication}

Not applicable

\section{Availability of data and material}


The datasets about the bacterial strain characterization generated and analyzed during the current study are available in the GenBank, NCBI at https://www.ncbi.nlm.nih.gov/nuccore/MG544095.1

\section{Competing interests}

The authors declare that they have no competing interests

\section{Funding}

The authors would appreciate the Vice Chancellor of Research and Technology, Falavarjan Branch, Islamic Azad University, Isfahan, Iran for their financial supports. This study was funded by a research grant number 301/28326 provided from Vice Chancellor of Research and Technology, Falavarjan Branch, Islamic Azad University, Isfahan, Iran.

\section{Authors' contributions}

KBM reviewed literatures and chose the subject. KBM and NSH conducted experiments. KBM wrote the paper and proofed data and text. All authors read and approved the final manuscript.

\section{Acknowledgements}

The authors thank to the Vice Chancellor of Research and Technology, Falavarjan Branch, Islamic Azad University, Isfahan, Iran for their technical supports and providing lab space.

\section{References}

[1] Beheshti-Maal K, Shafiei R. A thermotolerant Acetobacter strain isolated from Iranian peach suitable for industrial microbiology. Asian J Biol Sci. 2011;3:244-251

[2] Gullo M, Giudici P. Acetic acid in traditional balsamic vinegar, phenotypic traits relevant for starter cultures selection. Int J Food Microbiol. 2008;125:46-53

[3] La China S, Zanichelli G, De Vero L, Gullo M. Oxidative fermentations and exopolysaccharides production by acetic acid bacteria: a mini review. Biotechnol Lett. 2018;40:1289-1302

[4] Kocher GS, Kalra KL, Phutela RP. Comparative production of sugarcane vinegar by different immobilization techniques. J Inst Brew. 2006;112:264-266

[5] Beheshti-Maal K. Identification of a thermo-tolerant Acetobacterstrain isolated from Iranian date palm (Rotab) suitable for date vinegar production in agricultural biotechnology. Adv Environ Biol. 2014;10:1063-1071

[6] Ndoye B, Cleenwerck I, Engelbeen K, Dubois-Dauphin R, Guiro AT, et al. Acetobacter senegalensis sp. nov., a thermotolerant acetic acid bacterium isolated in Senegal (sub-Saharan Africa) from mango fruit (Mangifera indica). Int J Sys Evol Microbiol. 2007;57:1576-1581 
[7] Gomes RJ, Borges MF, Rosa MF, Castro-Gómez R, Spinosa WA. Acetic acid bacteria in the food industry: systematics, characteristics and applications. Food Technol Biotechnol. 2018;56:139-151

[8] Trček J, Barja F. Updates on quick identification of acetic acid bacteria with a focus on the 16S-23S rRNA gene internal transcribed spacer and the analysis of cell proteins by MALDI-TOF mass spectrometry. Int J Food Microbiol. 2015;196:137-144

[9] Klawpiyapamornkun T, Bovonsombut S, Bovonsombut S. Isolation and characterization of acetic acid bacteria from fruits and fermented fruit juices for vinegar production. Food Appl Biosci J. 2015;3:30-38

[10] Bellankimath A, Katti A, Hemalata VB, Meti BS. Isolation and characterization of the indigenous acetic acid bacteria from western ghats soil samples. Int J Curr Microbiol Appl Sci. 2017;9:1255-1265

[11] liha EC, Anna ES, Torres RC, Porto AC, Meinert EM. Utilization of bee (Apis mellifera) honey for vinegar production at laboratory scale. Acta Cie Ven. 2000;51:231-235

[12] Nanda K, Taniguchi M, Ujike S, Ishihara N, Mori H, Ono H, Muraoka Y. Characterization of acetic acid bacteria in traditional acetic acid fermentation of rice vinegar (komesu) and unpolished rice vinegar (kurosu) produced in Japan. Appl Environ Microbiol. 2001;67:986-990

[13] Giudici P, Rinaldi G. A theoretical model to predict the age of traditional balsamic vinegar. J Food Eng. 2007;82:121-127

[14] Gullo M, de Vero L, Giudici P. Succession of selected strains of Acetobacter pasteurianus and other acetic acid bacteria in traditional balsamic vinegar. Appl Environ Microbiol. 2009;175:2585-2589

[15] Falcone PM, Giudici P. Molecular size and molecular size distribution affecting traditional balsamic vinegar aging. J. Agr Food Chem. 2008;56:7057-7066

[16] Kadere TT, Miamoto T, Oniang'o RK, Kutima PM, Njoroge SM. Isolation and identification of genera Acetobacter and Gluconobacter in coconut toddy (mnazi). Afr J Biotechnol. 2008;7:2963-2971

[17] Drydale GS, Fleet GH. Acetic acid bacteria in some Australian wines. Food Technol Aust. 1985;37:1720

[18] Joyeux A, Lafon-Lafourcade S, Ribereau-Gayon P. Evolution of acetic acid bacteria during fermentation and storage of wine. Appl Environ Microbiol. 1984;48:153-156

[19] Beheshti-Maal K, Shafiee R. Isolation and characterization of an Acetobacter strain from Iranian white-red cherry as a potential strain for cherry vinegar production in microbial biotechnology. Asian $\mathrm{J}$ Biotechnol. 2010;1:53-59

[20] Beheshti-Maal K, Shafiee R. Isolation and identification of an Acetobacterstrain from Iranian whitered cherry with high acetic acid productivity as a potential strain for cherry vinegar production in food and 
agriculture biotechnology. World Acad Sci Eng Technol. 2009;54:201- 204

[21] Sharafi SM, Rasooli I, Beheshti-Maal K. Isolation, characterization and optimization of indigenous acetic acid bacteria and evaluation of their preservation methods. Iranian J Microbiol. 2010;1:41-48

[22] Beheshti-Maal K, Shafiei R, Kabiri N. Production of apricot vinegar using an isolated Acetobacter strain from Iranian apricot. Int J Biol Life Sci. 2010;4:230-233

[23] Sossou SK, Ameyapoh Y, Karau SD, de Souza C. Study of pineapple peelings processing into vinegar by biotechnology. Pak J Biol Sci. 2009;12:859-865

[24] Moryadee A, Pathom-Aree W. Isolation of thermotolerant acetic acid bacteria from fruits for vinegar production. Res J Microbiol, 2008;3:209-212

[25] Ogbona N. Microbiology of Nigerian palm wine with particular reference of bacteria. J Appl Bacteriol. 1993;38:81-88

[26] Faparusi SI. Origin of initial microflora of palm wine from oil palm trees (Elaeis guineensis). J Appl Bacteriol. 1973;36:559-565

[27] Amiri-Fahliyani S, Beheshti-Maal K, Ghandehari F. Novel lytic bacteriophages of Klebsiella oxytoca ABG-IAUF-1 as the potential agents for mastitis phage therapy. FEMS Microbiol Lett. 2018;20:1-8

[28] Berraud C. Production of highly concentrated vinegar in fed-batch culture. Biotechnol Lett. 2000;22:451-454

[29] Yetiman AE, Kesmen Z. Identification of acetic acid bacteria in traditionally produced vinegar and mother of vinegar by using different molecular techniques. Int J Food Microbiol. 2015;204:9-16

[30] Lino T, Suzuki R, Kosako Y, Ohkuma M, Komagata K, Uchimura T. Acetobacter okinawensis sp. nov., Acetobacter papayae sp. nov., and Acetobacter persicus sp. nov.; novel acetic acid bacteria isolated from stems of sugarcane, fruits, and a flower in Japan. J Gen Appl Microbiol. 2012;58:235-243

[31] Chen Z, Shi J, Yang X, Liu Y, Nan B, Wang Z. Isolation of exopolysaccharide-producing bacteria and yeasts from Tibetan kefir and characterization of the exopolysaccharides. Int $\mathrm{J}$ Dairy Technol. 2016;69:410-417

[32] Diba F, Alam F, Talukder AA. Screening of acetic acid producing microorganisms from decomposed fruits for vinegar production. Adv Microbiol. 2015;5:291-297

[33] lino T, Suzuki R, Kosako Y, Ohkuma M, Komagata K, Uchimura T. Acetobacter okinawensis sp. nov., Acetobacter papayae sp. nov., and Acetobacter persicus sp. nov.; novel acetic acid bacteria isolated from stems of sugarcane, fruits, and a flower in Japan. J Gen Appl Microbiol. 2012;58:235-243 


\section{Figures}

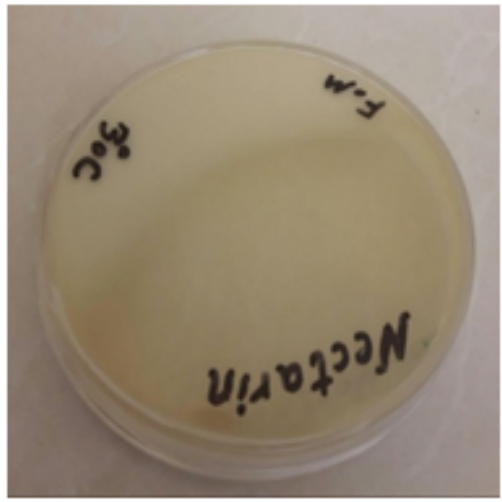

(A)

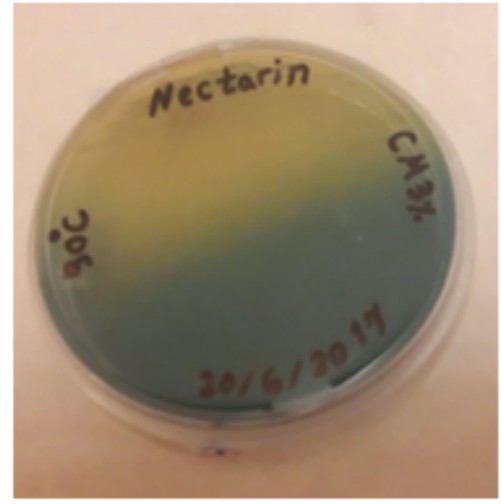

(B)

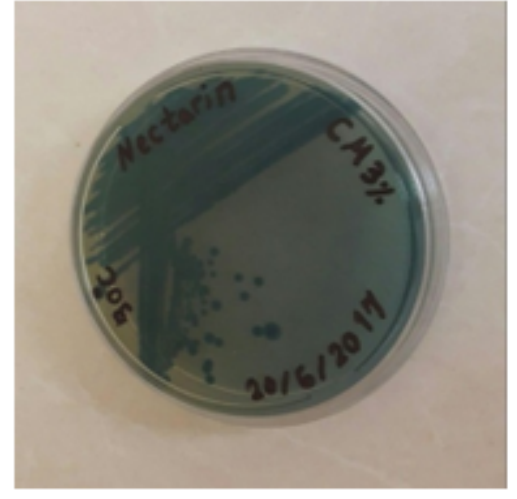

(C)

Figure 1

\section{Figure 1}

The isolation of $A A B$ from Iranian nectarine extract on selective culture media after 48 hour's incubation at $30^{\circ} \mathrm{C}$ on (A) Frateur culture medium and (B) Carr medium. (C) Overoxidation of Acetobacter sp. After 96 hours' incubation.

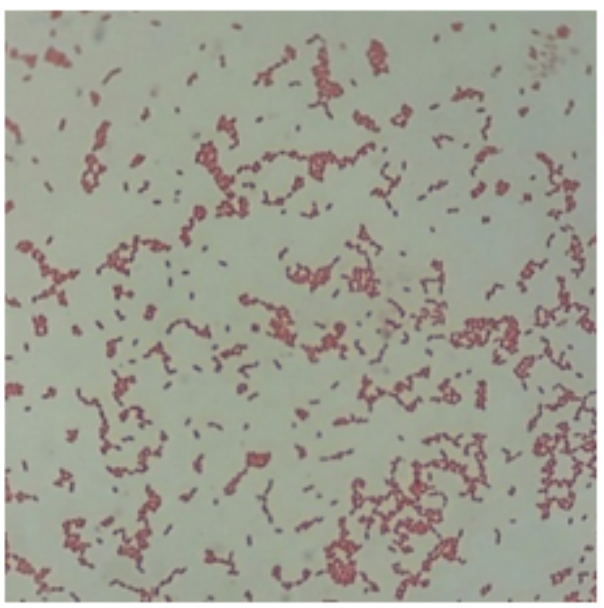

(A)

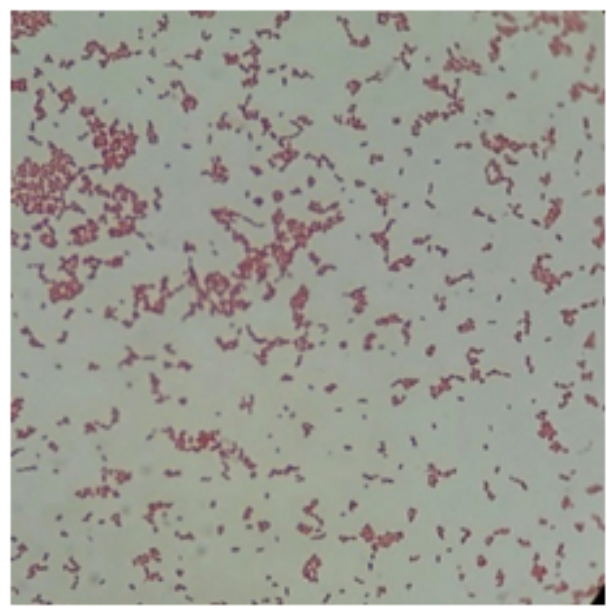

(B)

Figure 2

\section{Figure 2}

The Gram staining of Isolated Acetobacter from Iranian nectarine after 24 hours incubation at $30^{\circ} \mathrm{C}$ on (A) Carr medium and (B) Frateur medium. 


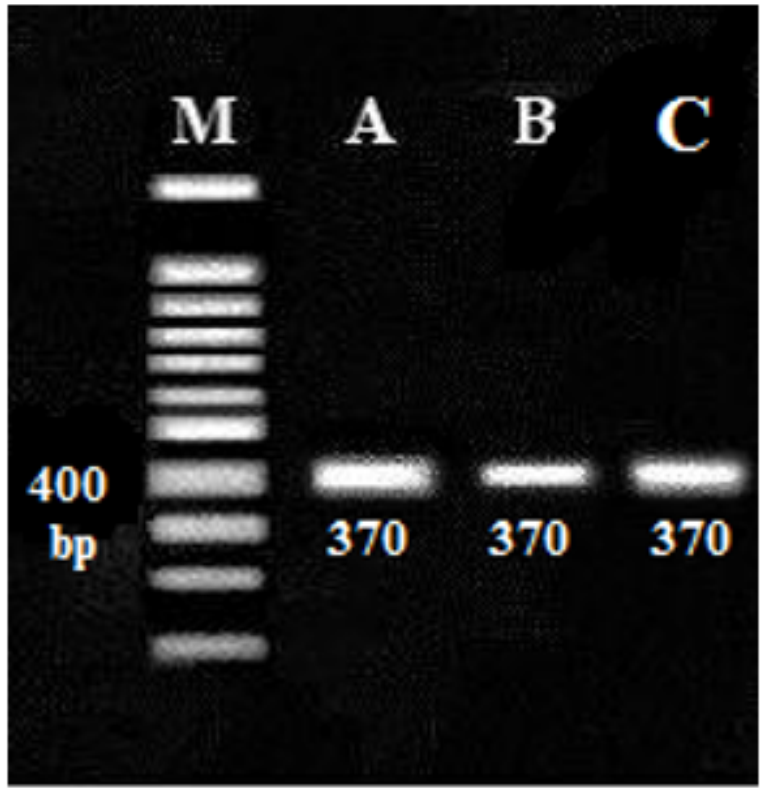

Figure 3

\section{Figure 3}

The PCR amplification of Acetobacter DNA isolated from Iranian nectarine using universal primers of OF $\mathrm{BUI}$ and OR BUI. M: 1500 bp marker, A: Acetobacter isolated from Iranian nectarine, B: positive control 1, Escherichia coli ATCC25922, C: positive control 2, Acetobacter aceti ATCC23746.

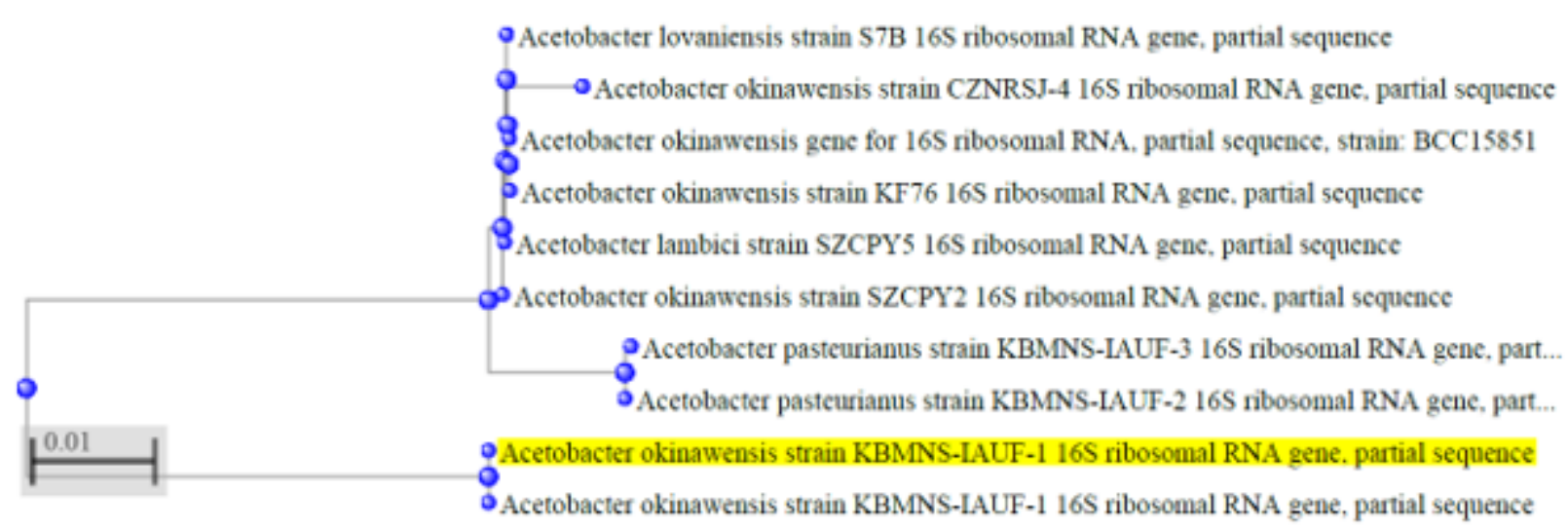

Figure 4

\section{Figure 4}

The phylogenic tree of different spp. of Acetobacter and the position of currently identified Acetobacter okinawensis KBMNS-IAUF-1. 
Acetic acid production by $A$. okinawensis KBMNS-IAUF-1

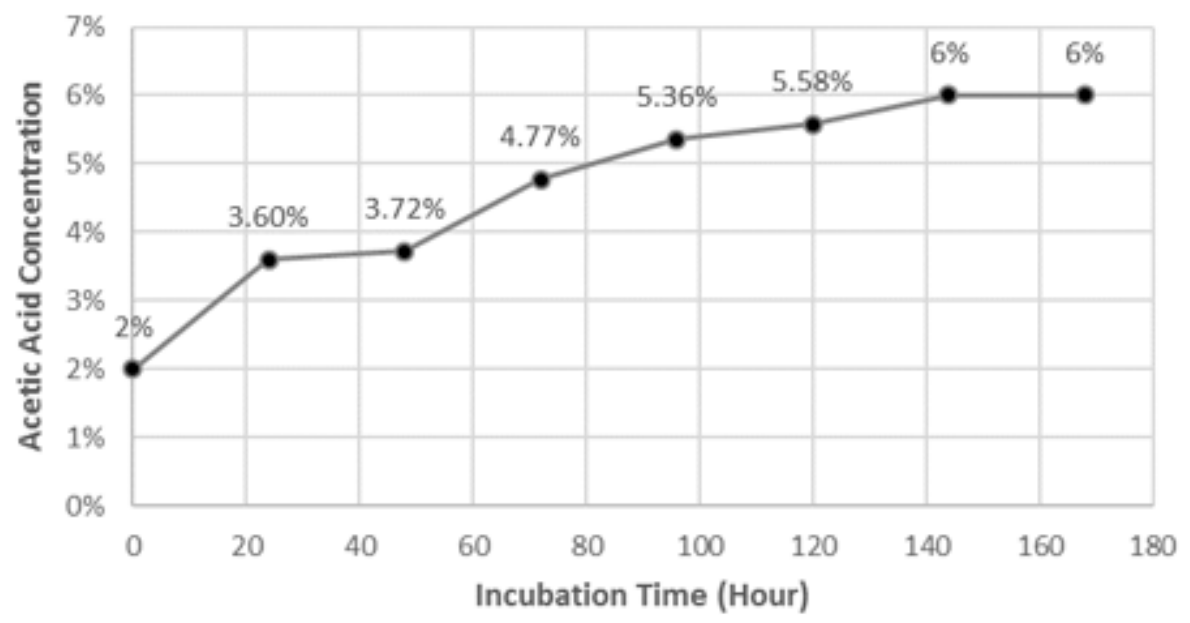

\section{Figure 5}

\section{Figure 5}

Acetic acid production by Acetobacter okinawensis KBMNS-IAUF-1 isolated from Iranian nectarine after 168 hours' incubation at $38^{\circ} \mathrm{C}$ and 16 LPM aeration speed in industrial culture medium using miniature glass fermentor.

\section{Supplementary Files}

This is a list of supplementary files associated with this preprint. Click to download.

- Tables.pdf 